\title{
Malnutrition is associated with worse health-related quality of life in children with cancer
}

\author{
Aeltsje Brinksma • Robbert Sanderman • Petrie F. Roodbol • Esther Sulkers • \\ Johannes G. M. Burgerhof • Eveline S. J. M. de Bont • Wim J. E. Tissing
}

Received: 3 October 2014 / Accepted: 22 February 2015 / Published online: 10 March 2015

(C) The Author(s) 2015. This article is published with open access at Springerlink.com

\begin{abstract}
Purpose Malnutrition in childhood cancer patients has been associated with lower health-related quality of life (HRQOL). However, this association has never actually been tested. Therefore, we aimed to determine the association between nutritional status and HRQOL in children with cancer.

Methods In 104 children, aged 2-18 years and diagnosed with hematological, solid, or brain malignancies, nutritional status and HRQOL were assessed at diagnosis and at 3,6, and 12 months using the child- and parent-report versions of the PedsQL 4.0 Generic scale and the PedsQL 3.0 Cancer Module. Scores on both scales range from 0 to 100 .

Results Undernourished children (body mass index (BMI) or fat-free mass $<-2$ standard deviation score (SDS)) reported significantly lower PedsQL scores compared with wellnourished children on the domains physical functioning $(-13.3)$, social functioning $(-7.0)$, cancer summary scale $(-5.9)$, and nausea $(-14.7)$. Overnourished children (BMI or fat mass $>2$ SDS) reported lower scores on emotional $(-8.0)$
\end{abstract}

A. Brinksma • E. Sulkers • E. S. J. M. de Bont • W. J. E. Tissing Department of Pediatric Oncology and Hematology Beatrix Children's Hospital, University of Groningen, University Medical Center Groningen, Groningen, The Netherlands

A. Brinksma $(\varangle) \cdot$ P. F. Roodbol $\cdot$ E. Sulkers

School of Nursing and Health, University of Groningen, University

Medical Center Groningen, PO Box 30.001, 9700

RB Groningen, The Netherlands

e-mail: a.brinksma@umcg.nl

\section{R. Sanderman}

Department of Health Sciences, Health Psychology Section, University of Groningen, University Medical Center Groningen, Groningen, The Netherlands

J. G. M. Burgerhof

Department of Epidemiology, University of Groningen, University Medical Center Groningen, Groningen, The Netherlands and cognitive functioning $(-9.2)$ and on the cancer summary scale (-6.6), whereas parent-report scores were lower on social functioning $(-7.5)$. Weight loss $(>0.5 \mathrm{SDS})$ was associated with lower scores on physical functioning $(-13.9$ child-report and -10.7 parent-report), emotional $(-7.4)$ and social functioning $(-6.0)$ (child-report), pain $(-11.6)$, and nausea $(-7.8)$ (parent-report). Parents reported worse social functioning and more pain in children with weight gain $(>0.5 \mathrm{SDS})$ compared with children with stable weight status.

Conclusions Undernutrition and weight loss were associated with worse physical and social functioning, whereas overnutrition and weight gain affected the emotional and social domains of HRQL. Interventions that improve nutritional status may contribute to enhanced health outcomes in children with cancer.

Keywords Childhood cancer · Nutritional status · Malnutrition · Obesity · Quality of life

\section{Introduction}

Malnutrition during treatment for childhood cancer not only has substantial clinical implications, but may also adversely affect a child's quality of life. Both undernutrition and overnutrition are common in children with cancer and can lead to more complications, higher relapse rates, and lower survival rates [1-3]. Metabolic alterations, reduced intake, and increased losses, caused by vomiting and diarrhea, can result in weight loss and ultimately lead to undernutrition [4]. At the same time, weight gain and alterations in body composition have frequently been reported in this particular patient group [5-7].

During the last two decades, improved survival rates have resulted in increased emphasis on children's personal needs. As a result, health-related quality of life (HRQOL) in children 
with cancer has become a critical issue in clinical practice. HRQOL is defined as "a multi-dimensional construct that includes physical, social and emotional functioning of the child, measured from the perspective of both the child and his or her family, and sensitive to the changes that occur throughout development [8]." The use of intensive treatments combining chemotherapy, surgery, and radiation causes many side effects which negatively affect children's HRQOL [9]. Generally, it is assumed that HRQOL in undernourished patients is lower compared with well-nourished patients [10] and that improvement of nutritional status will contribute to a better HRQOL. However, this association between nutritional status and HRQOL in children with cancer has never been tested.

In adult cancer patients, undernutrition and weight loss have been linked to lower scores on all domains of HRQOL [11-13]. Furthermore, overnutrition in healthy children has been linked to lower HRQOL scores as well [14]. Whether overnutrition has negative consequences for HRQOL in children with cancer is unknown.

The current study is the first to explore the association between nutritional status and HRQOL in children with cancer. HRQOL in children is preferably measured using both child self-report and parent proxy-report $[15,16]$. Children and parents do not necessarily have similar views on the impact of the disease [17]. Nevertheless, both reports provide valuable and complementary information toward a better understanding of the child's HRQOL. The objective of this study is to determine the association between undernutrition, overnutrition, weight loss, and weight gain and HRQOL in a heterogeneous sample of childhood cancer patients during the first year after diagnosis.

\section{Methods}

Participants

Participants were children between 2 and $<18$ years of age who were diagnosed with cancer between September 2007 and December 2009 and who were willing to participate in the Pediatric Cancer and Nutrition (PeCanNut) study [5] of the Pediatric Oncology Department of the University Medical Center Groningen (UMCG). Eligible patients were able to understand the Dutch language, received curative treatment, and were aged $\geq 5$ years for child-report of HRQOL or were aged $\geq 2$ years for parent proxy-report. A total of 128 patients met the inclusion criteria, of which 109 were aged $\geq 5$ years. Reasons for attrition are presented in Fig. 1. Nonresponders did not differ from participants with regard to age, gender, or type of malignancy. Ethical approval was obtained from the Medical Ethics Committee of the UMCG, and both parents and children aged $\geq 12$ years gave their written informed consent.

\section{Procedure}

Measurements were taken at diagnosis and at 3,6, and 12 months after diagnosis. These measurement times were chosen for practical reasons. The follow-up measurements were taken between courses of chemotherapy to make participation more acceptable to patients.

\section{Measures}

\section{Nutritional status}

Weight, height, and body mass index (BMI) were assessed and expressed as standard deviation scores (SDS) calculated from Dutch reference standards [18, 19]. Furthermore, fat-free mass (FFM) and fat mass (FM) were based on bioelectrical impedance analyses (BIA) using a $50-\mathrm{kHz}$ frequency BIA (BIA 101, Akern, Italy) and were expressed as SDS using Dutch reference values [20]. Details regarding measurements have been published previously [5].

Nutritional status was defined using both BMI and FM/ FFM cutoff values. BMI cutoff values were used because these are frequently used to define undernutrition or overnutrition. However, BMI does not reflect body composition adequately [21, 22]. Therefore, FM and FFM cutoff values were also used to define nutritional status. Undernutrition was defined as BMI $<-2$ SDS or FFM $<-2$ SDS, and overnutrition as BMI $>2$ SDS or FM $>2$ SDS. Children with both FFM $<-2$ SDS and FM $>2$ SDS and children aged $<4$ years were solely classified based on BMI.

Changes in weight following the previous measurement were expressed in changes in weight-for-age (WFA) SDS and as such controlled for normal growth during the study period. Relevant weight loss or weight gain was defined as $>0.5$ SDS WFA change. A 0.5 SDS increase or decrease corresponded to a weight change of up to $5 \%$. In children with cancer, weight loss $>5 \%$ was found to be associated with increased infection rates [23]. In adult patients, $5 \%$ weight loss is also used as a criterion for critical weight loss [24].

\section{Health-related quality of life}

The PedsQL measures are composed of parallel child selfreport formats (ages 5 years and older) and parent proxyreport formats (ages 2 years and older). The PedsQL 4.0 Generic Core Scale $[25,26]$ is a 23 -item, multidimensional scale designed to measure generic HRQOL and includes 4 subscales: physical, emotional, social, and school functioning. The subscales can be summed into total scale scores and psychosocial summary scores (composed of emotional, social, and school subscales).

The PedsQL Cancer Module [27] is a 27-item scale developed to measure cancer-specific HRQOL in children and 
Fig. 1 Flowchart patient inclusion and follow-up for child and parent report

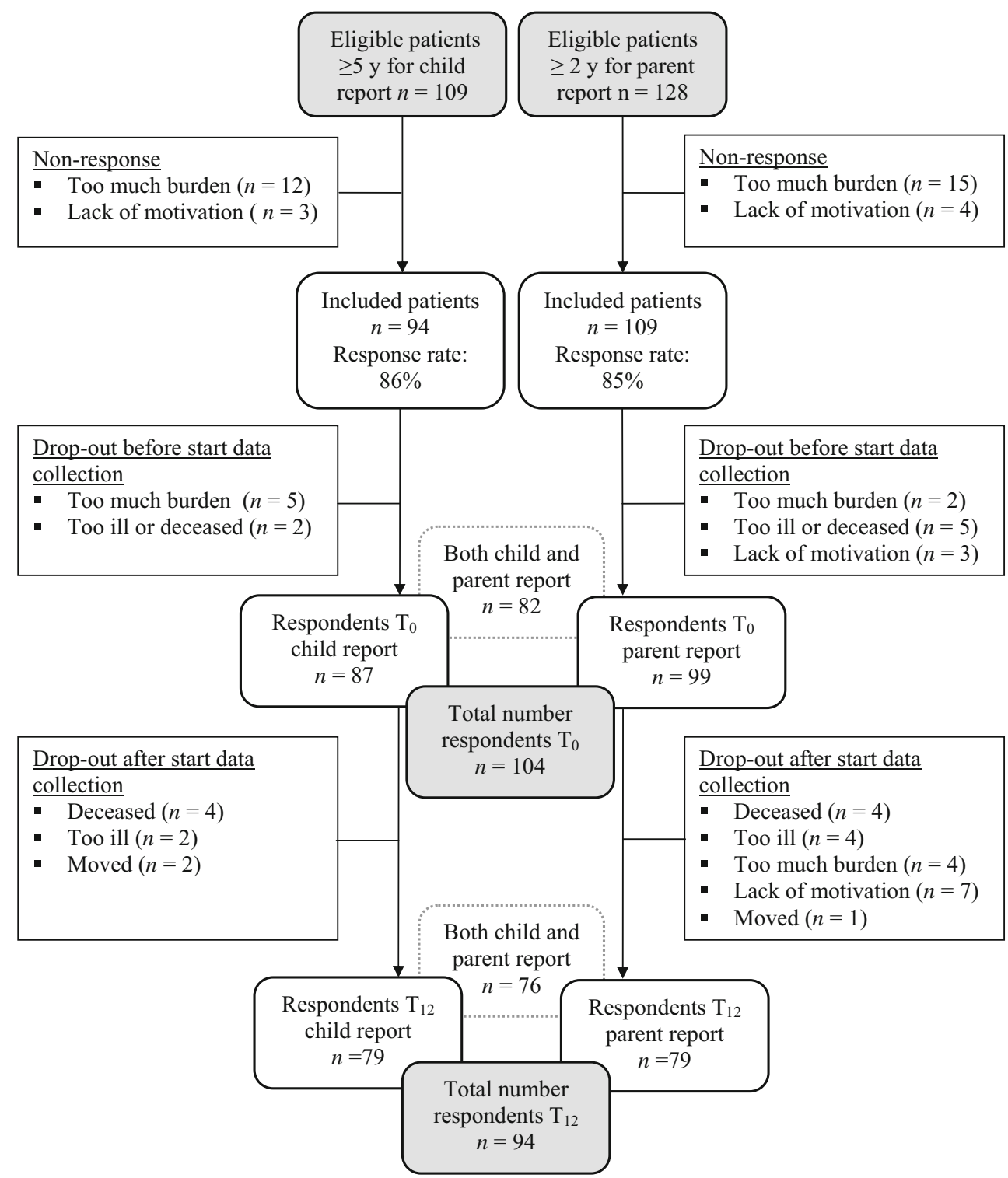

includes 8 subscales: pain and hurt, nausea, procedural anxiety, treatment anxiety, worry, cognitive problems, perceived physical appearance, and communication. A total scale score and scores on the subscales pain and hurt, nausea, cognitive problems, and perceived physical appearance were calculated. These subscales were considered to be relevant in relation to nutritional status.

To improve interpretability of the scores, the items of the 5point Likert scale were reversed and converted to a $0-100$ scale following standard procedures [28] so that higher scores indicated better HRQL. Both PedsQL instruments have high levels of reliability and validity [25-27, 29].

\section{Demographic and medical characteristics}

The following patient characteristics were included in the analyses: age, gender, socioeconomic status (SES), type of malignancy, treatment severity, and treatment phase. Treatment severity was measured with the Intensity of Treatment Rating Scale (ITR-3) [30]. Treatment phase was expressed as being on-active treatment or off-treatment. Off-treatment means that therapy was completed; the final round of chemotherapy was at least 1 month before the final measurement time. Education level of the father was included as a proxy for SES and stratified into three categories (low vocational education; intermediate vocational or general secondary education; higher professional or university education).

Data analysis and statistics

Prevalence rates of undernutrition, overnutrition, and the number of patients with relevant weight loss or weight gain were calculated. Given that the numbers of undernourished and overnourished children based on BMI or FM/FFM were rather 
small, and given that explorative plots of both classifications showed similar associations between nutritional status and HRQOL, the classifications were merged in the multilevel analyses to improve statistical power.

The course of the PedsQL scales over time was estimated using unconditional growth models (mixed models in SPSS). Paired $t$ tests were performed to compare child-report scores and parent-report scores.

In order to develop a powerful model and to prevent multiple testing by separate analyses at every measurement time, the association between HRQOL and undernutrition, overnutrition, and weight changes was analyzed using multilevel analyses (mixed models). We developed two series of predictive models of HRQOL as a function of time: one including the categories undernourished, overnourished, and wellnourished as predictors and one including weight loss, weight gain, and stable weight as predictors. Nutritional status was tested for main effects and interaction effects with time. Time was expressed as time in months. The well-nourished and stable weight groups were used as reference categories. The demographic factors and medical characteristics were included as covariables. These were first univariately tested for their association with either nutritional status or HRQOL by adding the variables to the unconditional growth model. Based on likelihood ratio tests, the covariables were selected for inclusion in the multivariate multilevel analyses. In the analyses using weight change as a predictor, BMI SDS at diagnosis was included to control for the difference in impact of weight changes on lean or obese children. To compare the outcomes of the conditional growth models of child self-report and parent proxy-report HRQOL, multilevel analyses of parent-report HRQOL were performed twice: once for all parent-report data (children 2-18 years of age) and once for those cases with available child-report data (children 5-18 years of age). All cases, including cases with missing data, were included for analyses. Statistical significance was accepted at the $5 \%$ level.

\section{Results}

Characteristics of the cohort

In total, 104 patients (aged 2-18 years) diagnosed with hematological (43\%), solid (33\%), or brain malignancies (24\%) participated in the study (Table 1). Of 87 patients, child-report data of the PedsQL were available, and of 99 patients, parentreport data were available at any given measurement time (Fig. 1). The majority of the patients received moderately intensive or very intensive treatment. During the study period, ten patients dropped out of the study. Reasons for loss to follow-up are presented in Fig. 1. After 12 months, $60 \%$ (56/94) of the patients had finished their treatment.
Table 1 Patients characteristics $(n=104)$

\begin{tabular}{|c|c|c|}
\hline \multicolumn{3}{|l|}{ Patients characteristics $(n=104)$} \\
\hline \multirow[t]{2}{*}{ Age median (range) } & 9.0 & $(2.0-17.7)$ \\
\hline & $n$ & $\%$ \\
\hline Gender: female & 56 & 54 \\
\hline \multicolumn{3}{|l|}{ Diagnosis: } \\
\hline Hematological & 45 & 43 \\
\hline Leukemia & 33 & 32 \\
\hline$-\mathrm{ALL}$ & 28 & 27 \\
\hline$-\mathrm{AML}$ & 5 & 5 \\
\hline Lymphoma & 12 & 12 \\
\hline Solid tumors & 34 & 33 \\
\hline Neuroblastoma & 7 & 7 \\
\hline Wilms tumors & 5 & 5 \\
\hline Bone & 8 & 8 \\
\hline Solid other & 14 & 14 \\
\hline Brain tumors & 25 & 24 \\
\hline Medullo- and ependymoblastoma & 6 & 6 \\
\hline Astrocytoma/glioma & 9 & 9 \\
\hline Craniopharyngioma & 4 & 4 \\
\hline Other & 6 & 6 \\
\hline \multicolumn{3}{|l|}{ Intensity of treatment rating (ITR) } \\
\hline Least intensive & 6 & 6 \\
\hline Moderate intensive & 51 & 49 \\
\hline Very intensive & 43 & 41 \\
\hline Most intensive & 4 & 4 \\
\hline \multicolumn{3}{|l|}{ Education level father ${ }^{\mathrm{a}}$} \\
\hline Low vocational education & 26 & 25 \\
\hline $\begin{array}{l}\text { Intermediate vocational/general secondary } \\
\text { education }\end{array}$ & 45 & 43 \\
\hline Higher professional/university education & 25 & 24 \\
\hline
\end{tabular}

${ }^{\mathrm{a}}$ Education level of the father was used as a proxy for socioeconomic status. For eight respondents, data about education level were missing

Descriptive statistics nutritional status and health-related quality of life

\section{Nutritional status}

The percentage of undernourished patients (BMI or FFM $<-2$ SDS) decreased from $19 \%$ at diagnosis to $10 \%$ after 12 months. For overnourished patients (BMI or FM $>2$ SDS), these percentages were 9 and $18 \%$, respectively. When using only BMI to define nutritional status, 8 to $1 \%$ were undernourished and 5 to $11 \%$ were overnourished at diagnosis and 12 months, respectively. Twenty-eight percent of the patients experienced weight loss $(>0.5$ SDS WFA), whereas $37 \%$ gained more than 0.5 SDS WFA during the measurement period. On average, $15 \%$ (range $0-36 \%$ ) of the patients were classified as malnourished in both classifications. They were 
undernourished and experienced $>0.5 \mathrm{SDS}$ weight loss or gain, or they were overnourished and experienced $>0.5$ SDS weight loss or gain. Details regarding the nutritional status of this cohort have been presented more extensively elsewhere [5].

\section{Health-related quality of life}

HRQOL improved during the study period. PedsQL total child-report improved from 67.4 (SD18.2) at diagnosis to 77.6 (SD 15.5) after 12 months (estimate slope 0.90 per month, $95 \%$ CI 0.59 ; $1.21, p<0.001)$. PedsQL total parentreport improved from 59.1 to 73.7 (estimate slope 1.12 per month, $95 \%$ CI $0.74 ; 1.51, p<0.001)$. Scores on PedsQL Cancer Module improved from 75.0 (SD 15.5) to 82.1 (SD12.0) (estimate slope 0.59 per month, $95 \%$ CI 0.33 ; $0.86, p<0.001)$ and from 71.9 (SD14.3) to 82.0 (SD14.7) (estimate slope 0.74 per month $95 \%$ CI $0.48 ; 1.01$, $p<0.001)$ for child- and parent-report, respectively. Parent proxy-report scores were lower than child-report scores on total PedsQL at all measurement times $(t=2.41$ to 4.08 , all $p$ values $<0.05)$ and on the PedsQL Cancer Module at diagnosis and at 3 months $(t=2.34, d f=74, p=0.022$ and $t=2.01$, $d f=67, p=0.041$, respectively).

\section{Covariable testing}

Univariate testing showed that type of malignancy and phase of treatment were related to nutritional status: children with brain malignancies had higher FM and lower FFM than children with hematological and solid malignancies, and children on-treatment had lower FFM than children off-treatment. Age, gender, type of malignancy, and phase of treatment were associated with HRQOL: older children, girls, children with brain malignancies, and children on-treatment reported lower HRQOL on one or more of the PedsQL summary scales or subscales. No relationship was found between SES or treatment intensity (neither classified in four groups nor in two groups) and HRQOL. Age, gender, type of malignancy, and phase of treatment were therefore included in the multilevel analyses to test whether differences in PedsQL scores were related to nutritional status or to one of the covariables.

Association between nutritional status and health-related quality of life

Multilevel analyses showed no interaction between nutritional status and time; thus, the trajectories of change in HRQOL over time were not significantly different for undernourished, overnourished, and well-nourished children (Figs. 2a-d and 3a-d) and for children with weight

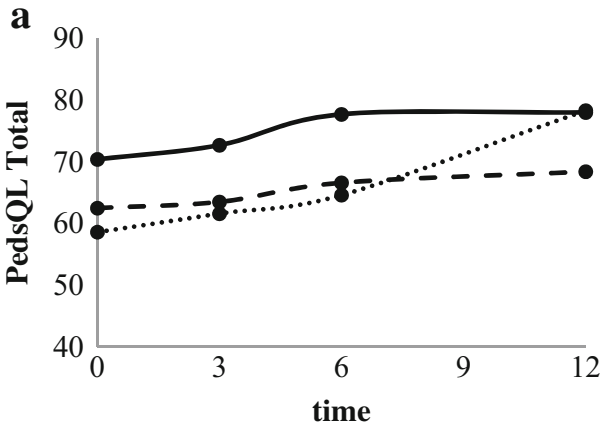

PedsQL Total child-report

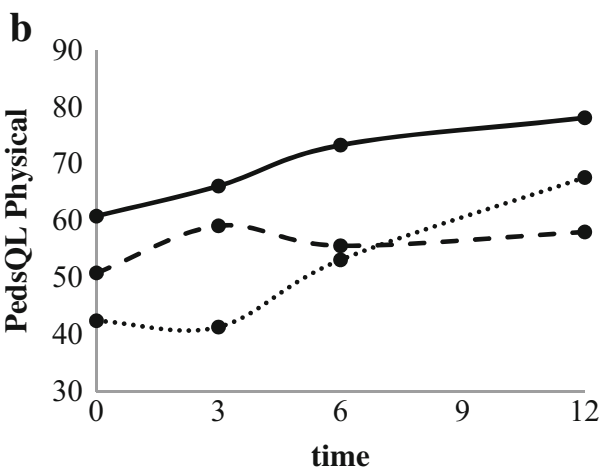

PedsQL Physical child-report

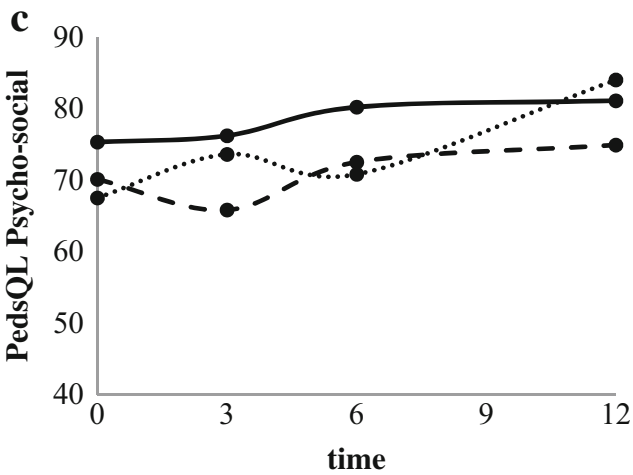

PedsQL Psycho-social child-report

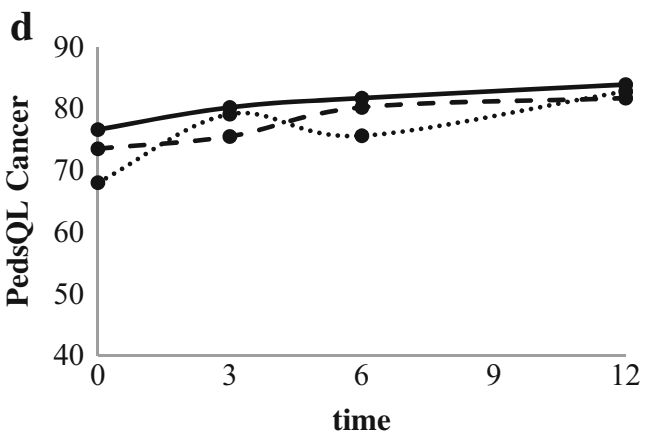

PedsQL Cancer child-report

Fig. 2 a PedsQL total child-report, b PedsQL physical child-report, c PedsQL psychosocial child-report, d PedsQL cancer child-report

loss, weight gain, and stable weight. For that reason, only main effects are reported. The results of the analyses of all parent-report data (ages 2-18 years) and 


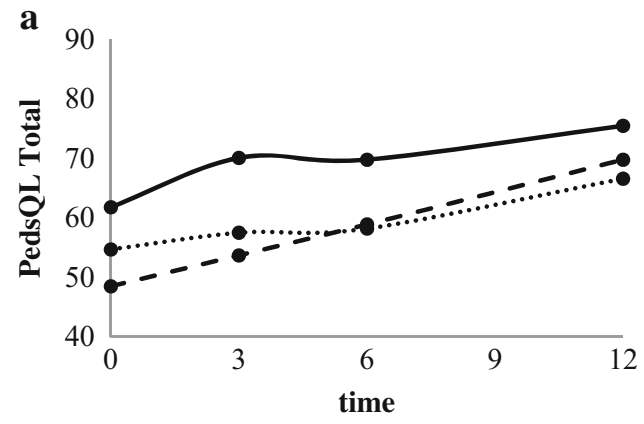

PedsQL Total parent-report

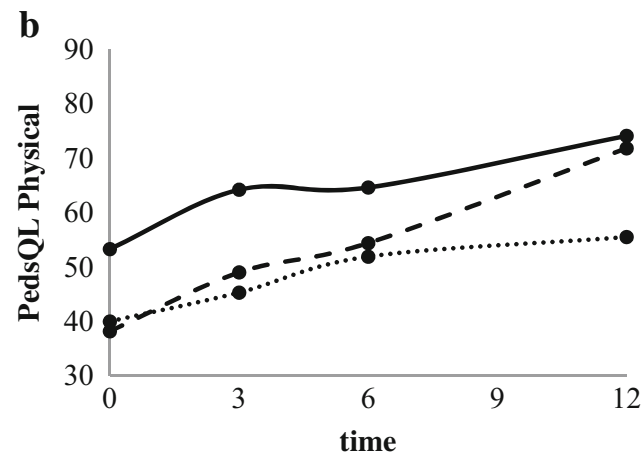

PedsQL Physical parent-report

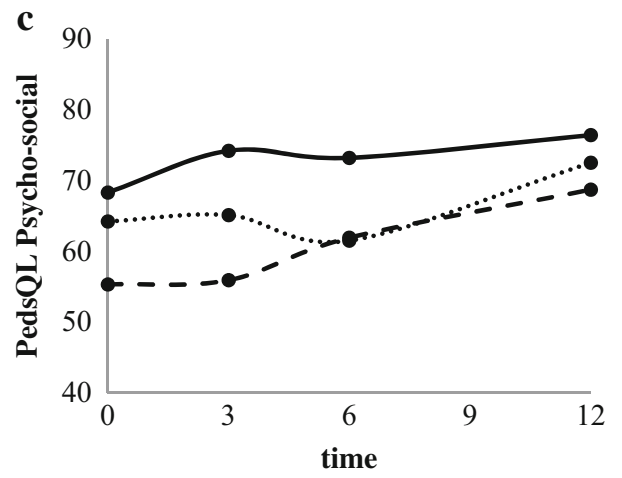

PedsQL Psycho-social parent-report

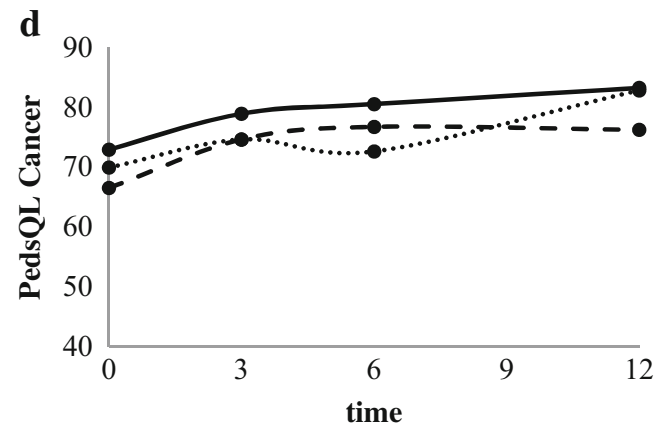

PedsQL Cancer parent-report

Fig. 3 a PedsQL total parent-report, b PedsQL physical parent-report, c PedsQL psychosocial parent-report, $\mathbf{d}$ PedsQL cancer parent-report

parent-report data of children aged 5-18 years were similar. Therefore, the results of the analyses of all parentreport data are presented.

\section{Undernutrition}

Undernourished patients reported significantly lower total PedsQL scores $(-6.0, p=0.003)$ (child-report) than wellnourished patients (Table 2, Fig. 2a). The differences were reflected in both physical and social functioning: undernourished patients scored $13.3(p=0.006)$ and $7.0(p=0.014)$ points lower, respectively. Undernourished patients also reported lower scores on the PedsQL Cancer Module $(-5.9, p=$ $0.013)$ and on the subscale nausea $(-14.7, p<0.001)$. Parentreport revealed no significant differences between undernourished and well-nourished patients on either one of the PedsQL scales (Table 3).

\section{Overnutrition}

Overnourished patients scored 5.4 points lower ( $p=$ 0.046 ) on the psychosocial summary scale (childreport) than well-nourished patients (Table 2, Fig. 2c). This difference was reflected in both emotional functioning $(-8.0, p=0.029)$ and social functioning $(-6.1$, $p=0.054)$. Overnourished patients reported lower scores on the PedsQL Cancer Module $(-6.6, p=0.013)$ and on the subscale cognitive problems $(-9.2, p=0.014)$. Parents of the overnourished patients scored lower on the psychosocial summary scale $(-7.5, p=0.028)$ and on social functioning $(-7.5, p=0.043)$ (Table 3$)$. Overnourished patients also scored lower on physical functioning; however, the differences were not statistically significant.

\section{Weight loss}

Children with weight loss $(>0.5$ SDS) scored 7.2 points lower $(p=0.008)$ on total PedsQL (child-report) compared with children with stable weight (Table 2). They scored lower on physical $(-13.9, p=0.004)$, emotional $(-7.4, p=$ $0.032)$, and social functioning $(-6.0, p=0.020)$ (Table 2). No differences were found for the PedsQL Cancer Module. Parent-reports were lower for PedsQL total $(-8.3, p=$ $0.016)$ and for physical functioning $(-10.7, p=0.034)$ (Table 3). Furthermore, parents reported more pain $(-11.6, p=0.021)$ and nausea $(-7.8, p=0.041)$ in children with weight loss.

\section{Weight gain}

Children with weight gain $(>0.5 \mathrm{SDS})$ had similar PedsQL scores on all scales compared with children with stable weight (child-report). Parent-reports of children with weight gain were 6.0 points lower $(p=0.040)$ on social functioning and 9.2 points lower $(p=0.049)$ on pain. 
Table 2 Association between nutritional status and HRQOL child-report $(n=87)$ based on two separate multilevel analyses

\begin{tabular}{|c|c|c|c|c|c|c|c|c|c|c|c|c|}
\hline & \multicolumn{6}{|c|}{ Reference group: well-nourished } & \multicolumn{6}{|c|}{ Reference group: stable weight } \\
\hline & \multicolumn{3}{|c|}{ Undernourished $^{\mathrm{b}}$} & \multicolumn{3}{|c|}{ Overnourished $^{\mathrm{c}}$} & \multicolumn{3}{|c|}{ Weight loss ${ }^{\mathrm{d}}$} & \multicolumn{3}{|c|}{ Weight gain ${ }^{\mathrm{d}}$} \\
\hline & Estimate & $95 \% \mathrm{CI}$ & $p$ & Estimate & $95 \% \mathrm{CI}$ & $p$ & Estimate & $95 \% \mathrm{CI}$ & $p$ & Estimate & $95 \%$ CI & $p$ \\
\hline Peds total & -6.0 & $-11.6 ;-.5$ & .033 & -6.0 & $-12.3 ; .4$ & .065 & -7.2 & $-12.4 ;-1.9$ & .008 & -.6 & $-5.2 ; 4.1$ & .812 \\
\hline Peds physical & -13.3 & $-22.9 ;-3.8$ & .006 & -7.9 & $-18.7 ; 2.9$ & .151 & -13.9 & $-23.3 ;-4.6$ & .004 & 1.5 & $-6.7 ; 9.7$ & .724 \\
\hline Peds psychosocial & -2.4 & $-7.1 ; 2.3$ & .319 & -5.4 & $-10.8 ;-.1$ & .046 & -4.2 & $-8.6 ; .2$ & .062 & -2.6 & $-6.5 ; 1.3$ & .186 \\
\hline Peds Emotional & 3.4 & $-3.1 ; 9.9$ & .303 & -8.0 & $-15.2 ;-.8$ & .029 & -7.4 & $-14.2 ;-.7$ & .032 & -5.3 & $-11.2 ; .7$ & .083 \\
\hline Peds social & -7.0 & $-12.6 ;-1.4$ & .014 & -6.1 & $-12.4 ; .1$ & .054 & -6.0 & $-11.1 ;-1.0$ & .020 & -2.4 & $-6.8 ; 2.1$ & .296 \\
\hline Peds school & -2.9 & $-10.6 ; 4.9$ & .467 & -4.0 & $-12.6 ; 4.5$ & .354 & .27 & $-7.7 ; 8.3$ & .947 & -1.4 & $-8.5 ; 5.7$ & .694 \\
\hline Peds cancer & -5.9 & $-10.6 ;-1.3$ & .013 & -6.6 & $-11.8 ;-1.4$ & .013 & -.9 & $-5.5 ; 3.7$ & .701 & 1.7 & $-2.3 ; 5.8$ & .397 \\
\hline Pain & -1.4 & $-11.4 ; 8.7$ & .788 & -4.6 & $-15.5 ; 6.2$ & .401 & -7.8 & $-19.0 ; 3.4$ & .170 & 4.0 & $-5.9 ; 13.9$ & .423 \\
\hline Nausea & -14.7 & $-22.7 ;-6.6$ & .000 & -5.5 & $-14.3 ; 3.4$ & .225 & 1.4 & $-6.9 ; 9.7$ & .738 & 5.7 & $-1.6 ; 13.1$ & .126 \\
\hline Cognition & -4.5 & $-10.9 ; 1.9$ & .164 & -9.2 & $-16.6 ;-1.9$ & .014 & -.4 & $-6.7 ; 6.0$ & .913 & -5.3 & $-11.0 ; .3$ & .064 \\
\hline Appearance & -.1 & $-8.0 ; 7.7$ & .972 & -5.6 & $-14.4 ; 3.2$ & .209 & 1.9 & $-6.0 ; 9.8$ & .632 & 1.9 & $-5.1 ; 8.8$ & .596 \\
\hline
\end{tabular}

The estimates in columns 2 and 3 represent the differences in PedsQL scores of undernourished or overnourished children compared with well-nourished children (reference group). The estimates in columns 4 and 5 represent the differences in PedsQL scores of children with weight loss or weight gain compared with children with stable weight (reference group). Estimates with significant p-value $(p<0.05)$ have been printed in bold

${ }^{a}$ Dependent variable PedsQL, independent variable nutritional status divided into three groups: undernourished, overnourished, and well-nourished; or weight loss, weight gain, stable weight. Reference category: well-nourished or stable weight. Included covariables are as follows: age, gender, type of malignancy, and phase of treatment

${ }^{\mathrm{b}}$ Based on $\mathrm{BMI}<-2$ SDS or FFM $<-2$ SDS

${ }^{\mathrm{c}}$ Based on $\mathrm{BMI}>2 \mathrm{SDS}$ or $\mathrm{FM}>2 \mathrm{SDS}$

${ }^{\mathrm{d}}$ Weight loss or weight gain $>0.5 \mathrm{SDS}$

CI confidence interval

\section{Discussion}

This is the first study to explore the association between nutritional status and HRQOL in children with cancer. The results of the PeCanNut study indicate that malnutrition is associated with worse HRQOL in children with cancer. Both undernourished children and overnourished children experienced worse HRQOL compared with well-nourished children. Significant weight loss and weight gain also contributed to worse HRQOL. To date, several studies have demonstrated worse HRQOL in undernourished adults, among others in adults with cancer [12, 13, 31-33]. In children, only two studies have demonstrated a positive association between nutritional status and HRQOL in children with cystic fibrosis $[34,35]$. To our best knowledge, the association between overnutrition and HRQOL has never been studied in cancer patients (adults or children).

Previous studies have shown that children treated for cancer have the lowest HRQOL when compared with healthy children or children with other diseases [25, 36-38]. The current study, however, demonstrates that with regards to nutritional status, undernourished and overnourished patients had the lowest HRQOL of all cancer patients. Impaired physical functioning was most prevalent in undernourished children and children with weight loss. It is well-known that undernutrition and weight loss are associated with loss of muscle mass and muscle weakness, resulting in fatigue [39]. Hence, undernourished children lacked the energy and muscle strength to participate in physical activities. In addition, undernourished children reported more side effects of treatment; they had lower scores on the PedsQL Cancer Module and experienced more pain and nausea. Pain and nausea have also been associated with fatigue [40], which impairs children's ability to cope with side effects of treatment. Furthermore, tolerance for (toxicity of) chemotherapy may be less in undernourished patients [4], resulting in more side effects. Finally, undernourished children reported impaired social functioning. This finding can be explained by the pain, nausea, and fatigue these children experience, which impairs their ability to fully participate in physical and social activities with their peers.

Compared with well-nourished children, overnourished children and children with weight gain reported worse functioning in the psychosocial domain, in particular in emotional and cognitive functioning, whereas parent-report scores were lower on social functioning. This implies that overnourished children did not feel well: they were more vulnerable to feelings of fear, sadness, and anger; experienced more difficulties in the interaction with other children; and experienced more 
Table 3 Association between nutritional status and HRQOL parent-report $(n=99)$ based on two separate multilevel analyses

\begin{tabular}{|c|c|c|c|c|c|c|c|c|c|c|c|c|}
\hline & \multicolumn{6}{|c|}{ Reference group: well-nourished } & \multicolumn{6}{|c|}{ Reference group: stable weight } \\
\hline & \multicolumn{3}{|c|}{ Undernourished $^{\mathrm{b}}$} & \multicolumn{3}{|c|}{ Overnourished $^{\mathrm{c}}$} & \multicolumn{3}{|c|}{ Weight loss ${ }^{\mathrm{d}}$} & \multicolumn{3}{|c|}{ Weight gain ${ }^{\mathrm{d}}$} \\
\hline & Estimate & $95 \%$ CI & $p$ & Estimate & $95 \% \mathrm{CI}$ & $p$ & Estimate & $95 \%$ CI & $p$ & Estimate & $95 \% \mathrm{CI}$ & $p$ \\
\hline Peds total & -3.0 & $-9.6 ; 3.6$ & .372 & -6.0 & $-13.7 ; 1.6$ & .122 & -8.3 & $-15.0 ;-1.5$ & .016 & -3.7 & $-10.0 ; 2.6$ & .252 \\
\hline Peds physical & -8.2 & $-18.1 ; 1.7$ & .104 & -4.9 & $-16.3 ; 6.6$ & .402 & -10.7 & $-20.6 ;-.8$ & .034 & -4.9 & $-14.0 ; 4.3$ & .297 \\
\hline Peds psychosocial & -.8 & $-6.6 ; 5.0$ & .778 & -7.5 & $-14.3 ;-.8$ & .028 & -5.2 & $-11.4 ; .93$ & .096 & -4.4 & $-10.0 ; 1.3$ & .130 \\
\hline Peds Emotional & .3 & $-7.0 ; 7.7$ & .927 & -6.6 & $-15.2 ; 2.1$ & .135 & -4.1 & $-11.4 ; 3.3$ & .275 & -2.5 & $-9.3 ; 4.3$ & .470 \\
\hline Peds social & -3.6 & $-9.7 ; 2.6$ & .253 & -7.5 & $-14.7 ;-.2$ & .043 & -6.1 & $-12.3 ; .1$ & .052 & -6.0 & $-11.7 ;-.3$ & .040 \\
\hline Peds school & 1.9 & $-8.1 ; 12.0$ & .708 & -8.2 & $-19.4 ; 3.0$ & .150 & -10.2 & $-20.8 ; .5$ & .061 & -3.7 & $-13.3 ; 5.9$ & .449 \\
\hline Peds cancer & -.0 & $-4.9 ; 4.8$ & .988 & -4.2 & $-10.1 ; 1.6$ & .156 & -3.1 & $-7.9 ; 1.7$ & .205 & -1.6 & $-6.0 ; 2.7$ & .463 \\
\hline Pain & 3.8 & $-5.6 ; 13.2$ & .426 & -9.4 & $-20.3 ; 1.6$ & .093 & -11.6 & $-21.4 ;-1.8$ & .021 & -9.2 & $-18.4 ;-.0$ & .049 \\
\hline Nausea & -6.4 & $-14.2 ; 1.4$ & .108 & -4.1 & $-13.4 ; 5.1$ & .376 & -7.8 & $-15.3 ;-.3$ & .041 & 3.8 & $-3.2 ; 10.9$ & .287 \\
\hline Cognition & 2.7 & $-4.7 ; 10.0$ & .477 & -5.4 & $-14.3 ; 3.4$ & .227 & .9 & $-6.6 ; 8.5$ & .811 & -6.6 & $-13.5 ; .3$ & .060 \\
\hline Appearance & -4.6 & $-12.4 ; 3.1$ & .239 & -8.5 & $-17.6 ; .5$ & .065 & -2.5 & $-9.8 ; 4.7$ & .493 & -3.1 & $-9.8 ; 3.5$ & .352 \\
\hline
\end{tabular}

The estimates in columns 2 and 3 represent the differences in PedsQL scores of undernourished or overnourished children compared with well-nourished children (reference group). The estimates in columns 4 and 5 represent the differences in PedsQL scores of children with weight loss or weight gain compared with children with stable weight (reference group). Estimates with significant p-value $(p<0.05)$ have been printed in bold

${ }^{a}$ Dependent variable PedsQL, independent variable nutritional status divided into three groups: undernourished, overnourished, and well-nourished; or weight loss, weight gain, stable weight. Reference category: well-nourished or stable weight. Included covariables are as follows: age, gender, type of malignancy, and phase of treatment

${ }^{\mathrm{b}}$ Based on $\mathrm{BMI}<-2$ SDS or FFM $<-2$ SDS

${ }^{\mathrm{c}}$ Based on $\mathrm{BMI}>2 \mathrm{SDS}$ or $\mathrm{FM}>2 \mathrm{SDS}$

${ }^{\mathrm{d}}$ Weight loss or weight gain $>0.5 \mathrm{SDS}$

CI confidence interval

difficulties in performing cognitive tasks than well-nourished children with cancer. A literature review [14] on HRQOL in healthy obese children and adolescents found that overweight had a negative impact on social and emotional functioning. Thus, the negative consequences of overweight in healthy children also apply to children with cancer. Contrary to obese healthy children, overnourished cancer patients did not experience worse physical functioning than well-nourished patients. It is likely that the impact of cancer and the subsequent intensive treatment on the children's physical functioning exceeded the impact of differences in nutritional status. Notably, overnourished children scored lower on cognitive functioning, whereas undernutrition is expected to be associated with lower performance on cognitive tasks [41]. Weight gain in undernourished children was expected to be associated with better outcomes in HRQOL. However, in the current sample, significant weight gain was predominantly seen in wellnourished children and not in undernourished children. Therefore, the potential benefit of weight gain in undernourished children was too small to affect the outcomes.

Contrary to our expectations, no association was found between intensity of treatment and HRQOL. So far, studies testing the association between intensity of treatment and HRQOL have shown contradictory results. Some found lower
HRQOL in ALL patients during the most intensive phase of treatment [42] or found an association between treatment intensity and HRQOL 6 weeks after diagnosis [43], whereas others found no association $[44,45]$. The heterogeneity of the sample, the low numbers of patients in the lowest and the highest category, and the classification of the ITR-3 into 4 broad categories, could possibly have influenced the relationship between treatment intensity and HRQOL.

An additional finding of this study was that children and parents reported differently on the association between nutritional status and HRQOL. The most significant difference between child- and parent-report concerned HRQOL in undernourished children: children reported significant impairments in several domains of HRQOL, whereas parent-report ratings failed to demonstrate differences between undernourished and well-nourished children. The fact that child- and parent-report had different outcomes does not reflect the lack of validity of either child- or parent-report. Rather, it reflects the different perspectives of children and parents on the child's HRQOL [46]. Children's perceptions, for example, are based on their subjective personal experiences with regard to symptoms such as fatigue, nausea, and pain. Children suffer from their undernourishment at first hand, whereas parents' view of their child's 
HRQOL is more indirect and relies on their external observations and on communication with the child [47].

Consistent with the literature $[16,47,48]$, in the current study, parent HRQOL ratings were lower than children's ratings. Parents are often more well-informed about treatment and prognosis, and they perceive cancer to have more negative consequences than children themselves. Moreover, their views may be influenced by the burden of care-giving, their own well-being, and other concerns [16]. Nevertheless, the perspectives of both children and parents complement each other and increase our understanding of the association between nutritional status and the child's HRQOL.

A limitation of the current study is that no causal impact between malnutrition and HRQOL could be demonstrated. Additionally, the heterogeneity of the sample could be seen as a disadvantage, for different malignancies have different treatment regimens with different side effects, and these side effects affect a child's HRQOL. On the other hand, the heterogeneity of the sample contributes to the generalizability of the findings to all children with cancer.

This study demonstrated that during treatment HRQOL in undernourished patients and patients with weight loss was significantly lower than in wellnourished patients. However, overnourished patients and patients with weight gain were also more vulnerable to negative feelings and performed worse in several domains of HRQOL. These findings have implications for clinical practice because they demonstrate the importance of an adequate nutritional status during treatment. Further research is needed to confirm whether nutritional interventions may contribute to better HRQOL outcomes in children with cancer. Finally, this study shows the added value of hearing both the children's and the parents' voices for a better understanding of children's HRQOL.

\begin{abstract}
Acknowledgments We are very grateful to all children and their parents for participating in the PeCanNut study, and we wish to thank Sonja Hintzen of the University Medical Center Groningen for her constructive advice and editing service.
\end{abstract}

Conflict of interest The authors have declared no conflict of interest. The authors have full control of all primary data and the authors agree to allow the journal to review their data if requested.

Funding None of the authors received funding for this study.

Open Access This article is distributed under the terms of the Creative Commons Attribution Noncommercial License which permits any noncommercial use, distribution, and reproduction in any medium, provided the original author(s) and the source are credited.

\section{References}

1. Lange BJ, Gerbing RB, Feusner J, Skolnik J, Sacks N, Smith FO et al (2005) Mortality in overweight and underweight children with acute myeloid leukemia. JAMA 293:203-211

2. Lobato-Mendizabal E, Lopez-Martinez B, Ruiz-Arguelles GJ (2003) A critical review of the prognostic value of the nutritional status at diagnosis in the outcome of therapy of children with acute lymphoblastic leukemia. Rev Investig Clin 55:31-35

3. Inaba H, Surprise HC, Pounds S, Cao X, Howard SC, RingwaldSmith K et al (2012) Effect of body mass index on the outcome of children with acute myeloid leukemia. Cancer 118:5989-5996. doi: 10.1002/cncr. 27640

4. Sala A, Pencharz P, Barr RD (2004) Children, cancer, and nutritionA dynamic triangle in review. Cancer 100:677-687

5. Brinksma A, Roodbol PF, Sulkers E, Kamps WA, de Bont ES, Boot AM et al (2015) Changes in nutritional status in childhood cancer patients: a prospective cohort study. Clin Nutr. 34:66-73. doi:10. 1016/j.clnu.2014.01.013

6. Murphy AJ, White M, Davies PS (2010) Body composition of children with cancer. Am J Clin Nutr 92:55-60

7. van der Sluis I, van den Heuvel-Eibrink MM, Hahlen K, Krenning EP, de Muinck Keizer-Schrama SM (2002) Altered bone mineral density and body composition, and increased fracture risk in childhood acute lymphoblastic leukemia. J Pediatr 141:204-210

8. Bradlyn AS, Ritchey AK, Harris CV, Moore IM, O'Brien RT, Parsons SK et al (1996) Quality of life research in pediatric oncology. research methods and barriers. Cancer 78:1333-1339

9. Nathan PC, Furlong W, Barr RD (2004) Challenges to the measurement of health-related quality of life in children receiving cancer therapy. Pediatr Blood Cancer 43:215-223

10. Ladas EJ, Sacks N, Meacham L, Henry D, Enriquez L, Lowry G et al (2005) A multidisciplinary review of nutrition considerations in the pediatric oncology population: a perspective from children's oncology group. Nutr Clin Pract 20:377-393

11. Capuano G, Gentile PC, Bianciardi F, Tosti M, Palladino A, Di Palma M (2010) Prevalence and influence of malnutrition on quality of life and performance status in patients with locally advanced head and neck cancer before treatment. Support Care Cancer 18:433-437

12. Ravasco P, Monteiro-Grillo I, Vidal PM, Camilo ME (2004) Cancer: disease and nutrition are key determinants of patients' quality of life. Support Care Cancer 12:246-252

13. Nourissat A, Vasson MP, Merrouche Y, Bouteloup C, Goutte M, Mille D et al (2008) Relationship between nutritional status and quality of life in patients with cancer. Eur J Cancer 44:1238-1242

14. Tsiros MD, Olds T, Buckley JD, Grimshaw P, Brennan L, Walkley J et al (2009) Health-related quality of life in obese children and adolescents. Int J Obes 33:387-400. doi:10.1038/ijo.2009.42

15. Hinds PS (2010) Progress in quality of life in children and adolescents with cancer. Semin Oncol Nurs 26:18-25. doi:10.1016/j.soncn. 2009.11.004

16. Eiser C, Morse R (2001) Can parents rate their child's health-related quality of life? results of a systematic review. Qual Life Res 10:347357

17. Eiser C, Morse R (2001) A review of measures of quality of life for children with chronic illness. Arch Dis Child 84:205-211

18. Fredriks AM, van Buuren S, Burgmeijer RJ, Meulmeester JF, Beuker RJ, Brugman E et al (2000) Continuing positive secular growth change in the netherlands 1955-1997. Pediatr Res 47:316-323

19. Gerver WJM, de Bruin R (2001) Paediatric morphometrics. A reference manual. Universitaire Pers Maastricht, Maastricht

20. Boot AM, Bouquet J, deRidder MAJ, Krenning EP, KeizerSchrama SMPF (1997) Determinants of body composition measured by dualenergy X-ray absorptiometry in dutch children and adolescents. Am J Clin Nutr 66:232-238 
21. Fusch G, Raja P, Dung NQ, Karaolis-Danckert N, Barr R, Fusch C (2013) Nutritional status in sick children and adolescents is not accurately reflected by BMI-SDS. J Am Coll Nutr 32:407-416. doi:10. 1080/07315724.2013.848156

22. Javed A, Jumean M, Murad MH, Okorodudu D, Kumar S, Somers VK et al (2014) Diagnostic performance of body mass index to identify obesity as defined by body adiposity in children and adolescents: a systematic review and meta-analysis. Pediatr Obes. doi:10.1111/ ijpo. 242

23. Loeffen EA, Brinksma A, Miedema KG, de Bock GH, Tissing WJ (2015) Clinical implications of malnutrition in childhood cancer patients-infections and mortality. Support Care Cancer. 23:143150. doi:10.1007/s00520-014-2350-9

24. Stratton RJ, Green CJ, Elia M (2003) Disease related malnutrition, an evidence based approach to treatment. CAB International, Wallingford Oxon

25. Varni JW, Seid M, Kurtin PS (2001) PedsQL 4.0: reliability and validity of the pediatric quality of life inventory version 4.0 generic core scales in healthy and patient populations. Med Care 39:800-812

26. Varni JW, Limbers CA, Burwinkle TM (2007) Parent proxy-report of their children's health-related quality of life: an analysis of 13,878 parents' reliability and validity across age subgroups using the PedsQL 4.0 generic core scales. Health Qual Life Outcomes 5:2. doi:10.1186/1477-7525-5-2

27. Varni JW, Burwinkle TM, Katz ER, Meeske K, Dickinson P (2002) The PedsQL in pediatric cancer: reliability and validity of the pediatric quality of life inventory generic core scales, multidimensional fatigue scale, and cancer module. Cancer 94:2090-2106

28. Varni JW. PedsQL scoring algorithm; scoring the pediatric quality of life inventory. 1998-2014

29. Varni JW, Limbers CA, Burwinkle TM (2007) How young can children reliably and validly self-report their health-related quality of life?: an analysis of 8,591 children across age subgroups with the PedsQL 4.0 generic core scales. Health Qual Life Outcomes 5:1. doi:10.1186/1477-7525-5-1

30. Kazak AE, Hocking MC, Ittenbach RF, Meadows AT, Hobbie W, DeRosa BW et al (2012) A revision of the intensity of treatment rating scale: classifying the intensity of pediatric cancer treatment. Pediatr Blood Cancer 59:96-99. doi:10.1002/pbc.23320

31. Marin Caro MM, Laviano A, Pichard C (2007) Impact of nutrition on quality of life during cancer. Curr Opin Clin Nutr Metab Care 10: 480-487

32. Gupta D, Lis CG, Granick J, Grutsch JF, Vashi PG, Lammersfeld CA (2006) Malnutrition was associated with poor quality of life in colorectal cancer: a retrospective analysis. J Clin Epidemiol 59:704-709. doi:10.1016/j.jclinepi.2005.08.020

33. Andreyev HJ, Norman AR, Oates J, Cunningham D (1998) Why do patients with weight loss have a worse outcome when undergoing chemotherapy for gastrointestinal malignancies? Eur J Cancer 34: 503-509

34. Shoff SM, Tluczek A, Laxova A, Farrell PM, Lai HJ (2013) Nutritional status is associated with health-related quality of life in children with cystic fibrosis aged 9-19 years. J Cyst Fibros 12:746753. doi:10.1016/j.jcf.2013.01.006

35. Bodnar R, Kadar L, Holics K, Ujhelyi R, Kovacs L, Bolbas K et al (2014) Factors influencing quality of life and disease severity in hungarian children and young adults with cystic fibrosis. Ital J Pediatr 40: 50. doi:10.1186/1824-7288-40-50

36. Varni JW, Limbers C, Burwinkle TM (2007) Literature review: health-related quality of life measurement in pediatric oncology: Hearing the voices of the children. J Pediatr Psychol 32:1151-1163

37. Varni JW, Seid M, Smith Knight T, Burwinkle T, Brown J, Szer IS (2002) The PedsQL in pediatric rheumatology: reliability, validity, and responsiveness of the pediatric quality of life inventory generic core scales and rheumatology module. Arthritis Rheum 46:714-725

38. Varni JW, Burwinkle TM, Jacobs JR, Gottschalk M, Kaufman F, Jones KL (2003) The PedsQL in type 1 and type 2 diabetes: reliability and validity of the pediatric quality of life inventory generic core scales and type 1 diabetes module. Diabetes Care 26:631-637

39. Evans WJ, Lambert CP (2007) Physiological basis of fatigue. Am J Phys Med Rehabil 86:S29-46

40. Rodgers CC, Hooke MC, Hockenberry MJ (2013) Symptom clusters in children. Curr Opin Support Palliat Care 7:67-72. doi:10.1097/ SPC.0b013e32835ad551

41. Benton D (2010) The influence of dietary status on the cognitive performance of children. Mol Nutr Food Res 54:457-470. doi:10. 1002/mnfr.200900158

42. Furlong W, Rae C, Feeny D, Gelber RD, Laverdiere C, Michon B et al (2012) Health-related quality of life among children with acute lymphoblastic leukemia. Pediatr Blood Cancer 59:717-724. doi:10. $1002 / p b c .24096$

43. Landolt MA, Vollrath M, Niggli FK, Gnehm HE, Sennhauser FH (2006) Health-related quality of life in children with newly diagnosed cancer: a one year follow-up study. Health Qual Life Outcomes 4:63. doi:10.1186/1477-7525-4-63

44. Parsons SK, Fairclough DL, Wang J, Hinds PS (2012) Comparing longitudinal assessments of quality of life by patient and parent in newly diagnosed children with cancer: the value of both raters' perspectives. Qual Life Res 21:915-923. doi:10.1007/s11136-0119986-4

45. Barakat LP, Marmer PL, Schwartz LA (2010) Quality of life of adolescents with cancer: family risks and resources. Health Qual Life Outcomes 8:63. doi:10.1186/1477-7525-8-63

46. Hughes AR, Farewell K, Harris D, Reilly JJ (2007) Quality of life in a clinical sample of obese children. Int J Obes 31:39-44. doi:10.1038/ sj.ijo.0803410

47. Levi RB, Drotar D (1999) Health-related quality of life in childhood cancer: discrepancy in parent-child reports. Int J Cancer Suppl 12:5864

48. Chang PC, Yeh CH (2005) Agreement between child self-report and parent proxy-report to evaluate quality of life in children with cancer. Psycho-Oncology 14:125-134 